\title{
Infecções humanas causadas por poxvirus relacionados ao vírus vaccinia no Brasil
}

\author{
Human infections caused by vaccinia-like poxviruses in Brazil
}

\author{
Hermann G. Schatzmayr ${ }^{1}$, Renata Vitória Campos Costa ${ }^{2}$, Márcia Cristina Rosa Gonçalves ${ }^{1}$, \\ Débora Ferreira Barreto ${ }^{1}$, Valéria Holmo Batista ${ }^{3}$, Manuel Enderson Vieira Silva ${ }^{1}$, \\ Luis Armando Calvão Brust ${ }^{2}$ e Ortrud Monika Barth ${ }^{1}$
}

\begin{abstract}
RESUMO
A partir de 1999, infecções humanas por Orthopoxvirus vem sendo observadas em pelo menos oito estados no país, com a formação de vesículas as quais evoluem para pústulas e crostas, principalmente nos membros superiores e face, após contacto com bovinos apresentando lesões semelhantes no úbere. Alem das lesões na pele, foram descritas nos pacientes reações ganglionares axilares por vezes dolorosas, febre, cefaléia, fadiga, desidratação, anorexia, sudorese, artralgia e mialgia, evoluindo o quadro por três a quatro semanas. Lesão vulvar bem como transmissão intrafamiliar foram igualmente descritas. Estudos moleculares demonstraram que os poxvirus identificados são geneticamente relacionados a amostras do vírus vaccinia utilizadas no passado, nas campanhas de vacinação. Especimens clínicos de 80 infecções humanas foram estudados no laboratório e a infecção por orthopoxvirus confirmada em 68 casos. São apresentadas lesões observadas em pacientes bem como discutidas as implicações desta zoonose no Brasil.
\end{abstract}

Palavras-chaves: Orthopoxvirus. Vírus vaccinia-like. Infecções humanas. Brasil.

\begin{abstract}
Since 1999, human infection caused by Orthopoxvirus has been observed in at least eight Brazilian states, with the presence of vesicles that evolve to pustules and crusts, especially on the hands, arms and face, after contact with cows showing comparable lesions on the udder. In addition to the skin lesions, there have been descriptions of patients with axillary ganglionic reactions that are sometimes painful, along with fever, headache, fatigue, dehydration, anorexia, sudoresis, arthralgia and muscle pain. The condition evolves over a three to four-week period. Vulvar lesions and transmission within families have also been described. Molecular studies have shown that the poxviruses identified are genetically related to vaccinia virus samples that were used in vaccination campaigns in the past. Clinical specimens from 80 human infections were studied in the laboratory, and orthopoxvirus infections were confirmed in 68 cases. The lesions observed in these patients are presented and the implications of this zoonosis in Brazil are discussed.
\end{abstract}

Key-words: Orthopoxvirus. Vaccinia-like viruses. Human infections. Brazil.

A familia Poxviridae infecta tanto vertebrados como invertebrados sendo o gênero Orthopoxvirus o mais importante do ponto de vista da infecção em humanos ${ }^{16}$. Este gênero inclui o vírus da varíola, erradicado desde 1977, o vírus vaccinia, usado na produção de vacinas, o monkeypox, vírus de origem africana e que foi introduzido nos Estados Unidos pela importação de animais de estimação ${ }^{7}$ e o cowpox, vírus que circula em roedores na Europa e Oriente Médio, vindo a infectar felinos e, eventualmente, o homem. 0 gênero causa doença vesicular aguda, com diferentes graus de gravidade para o hospedeiro.

1. Laboratório de Morfologia e Morfogênese Viral, Instituto Oswaldo Cruz, Rio de Janeiro, RJ. 2. Secretaria da Agricultura, Pecuária, Pesca e Abastecimento, Rio de Janeiro, RJ. 3. Departamento de Ginecologia, Escola de Medicina, Universidade de São Paulo, São Paulo, SP. 4. Médico-Veterinário.

Endereço para correspondência: Dr. Hermann G. Schatzmayr. Laboratório de Morfologia e Morfogênese Viral/FIOCRUZ. Av. Brasil 4365, Pavilhão Helio e Peggy Pereira, 21045-900 Rio de Janeiro, RJ.

Tel: $55212562-1749$

e-mail: hermann@ioc.fiocruz.br

Recebido para publicação em 26/05/2009

Aceito em 19/11/2009
No Brasil, as campanhas de vacinação foram realizadas nas zonas rurais por equipes que se deslocavam de uma propriedade à outra, manipulando os frascos contendo a vacina viva com 0 vírus vaccinia em altos títulos, sendo comum a não eliminação adequada dos materiais residuais, contendo restos do imunizante. Admite-se que estes procedimentos permitiram a implantação de amostras do vírus vaccinia em ciclos naturais, pela infecção de animais reservatórios, como roedores silvestres, vindo a atingir posteriormente bovinos e pessoas que manejam estes animais. Um laboratório para o estudo destas infecções foi montado no Instituto Oswaldo Cruz, descrevendo-se neste artigo a experiência obtida no estudo de casos humanos ao longo dos últimos 10 anos.

\section{MATERIAL E MÉTODOS}

Pacientes estudados. Espécimens clínicos, compreendendo líquidos de vesículas/pústulas, crostas e amostras de soro, foram recebidos de 80 pacientes, originários dos Estados do Rio de Janeiro, Espírito Santo, Minas Gerais, Mato Grosso, São Paulo e 
Mato Grosso do Sul. Os materiais foram encaminhados através de autoridades de saúde municipais ou estaduais ou diretamente dos médicos assistentes. Uma descrição clínica, embora por vezes bastante sumária, foi recebida da maioria dos pacientes, tendo sido fotografadas as lesões de alguns casos que formalmente consentiram no procedimento. A Comissão de Ética em Pesquisa em Seres Humanos da Fundação Oswaldo Cruz aprovou o manejo dos especimens destes casos no Laboratório de Morfologia e Morfogênese Viral do Instituto Oswaldo Cruz.

Microscopia eletrônica. Suspensões dos fluidos vesiculares, pustulares e de macerados de crostas foram contrastadas ${ }^{2}$ com ácido fosfotúngstico a 1\% em água destilada e observadas em microscópio eletrônico Zeiss modelo EM-900, para a visualização de partículas de poxvirus.

Reação em cadeia da polimerase. Utilizou-se o par de primers HAOUT'R e HAOUTF ${ }^{4}$, amplificando-se um fragmento com cerca de 1.171 pares de base do gene da hemaglutinina. Aplicouse 0 kit comercial de Reação em cadeia da polimerase master MIX (Promega Corporation), com 25 pmol de cada primer, $5 \mu \mathrm{l}$ da amostra e volume final de 100 $\mu$ l. O material foi amplificado em termo-ciclador (PTC 100 programable Thermal Controler-MJR Research) utilizando-se a seguinte ciclagem: um ciclo prévio de $95^{\circ} \mathrm{C}-3 \mathrm{~min}, 4^{\circ} \mathrm{C}-10 \mathrm{~min}, 35$ ciclos de $94^{\circ} \mathrm{C}-1 \min .50^{\circ} \mathrm{C}-$ $1 \mathrm{~min}, 72^{\circ} \mathrm{C}-1$ min e 30 segundos, seguidos de uma extensão de $72^{\circ} \mathrm{C}$ por 7 minutos. Como controle negativo, incluiu-se água $\mathrm{mQ}$ e como controle positivo foi utilizado uma amostra do vírus vacinal amostra Wyeth. 0 material amplificado foi submetido a gel de eletroforese em agarose a 1,5\%, corado com brometo de etídio e visualizado em transiluminador, através da incidência de luz ultravioleta (Figura 1).

Isolamento de vírus. Os espécimens de líquidos vesiculares/ pústulares e macerados de crostas foram tratados com antibióticos e inoculados em uma linhagem de células Vero. Os casos apresentando efeito sobre as células foram confirmados por microscopia eletrônica e reação molecular (PCR).

Determinação de anticorpos. Utilizou-se uma reação de redução de $50 \%$ de placas, sendo $100 \mu 1$ dos soros diluídos de $1 / 10$ a 1/1.280, misturados com 100l de uma suspensão de vírus da amostra Cantagalo/IOC, isolado de um caso clínico naquele município do Estado do Rio de Janeiro em 1999. Após incubação por uma hora a $37^{\circ} \mathrm{C}$, a mistura soro-vírus foi distribuída em microplacas de fundo chato, adicionando-se uma suspensão de células Vero e incubando-se por 48 horas a $37^{\circ} \mathrm{C}$. As placas foram coradas com cristal violeta e formol e foi realizada a contagem das placas formadas, registrando-se como o título dos anticorpos a menor diluição de soro capaz de reduzir $50 \%$ do número de placas do controle de vírus, incluído no teste.

\section{RESULTADOS}

Dos 80 pacientes estudados, foram recebidas 19 amostras de líquido vesicular/pustular, 13 crostas e 77 amostras de soro, sendo 10 delas pareadas, incluindo uma amostra da fase aguda e outra da fase convalescente.

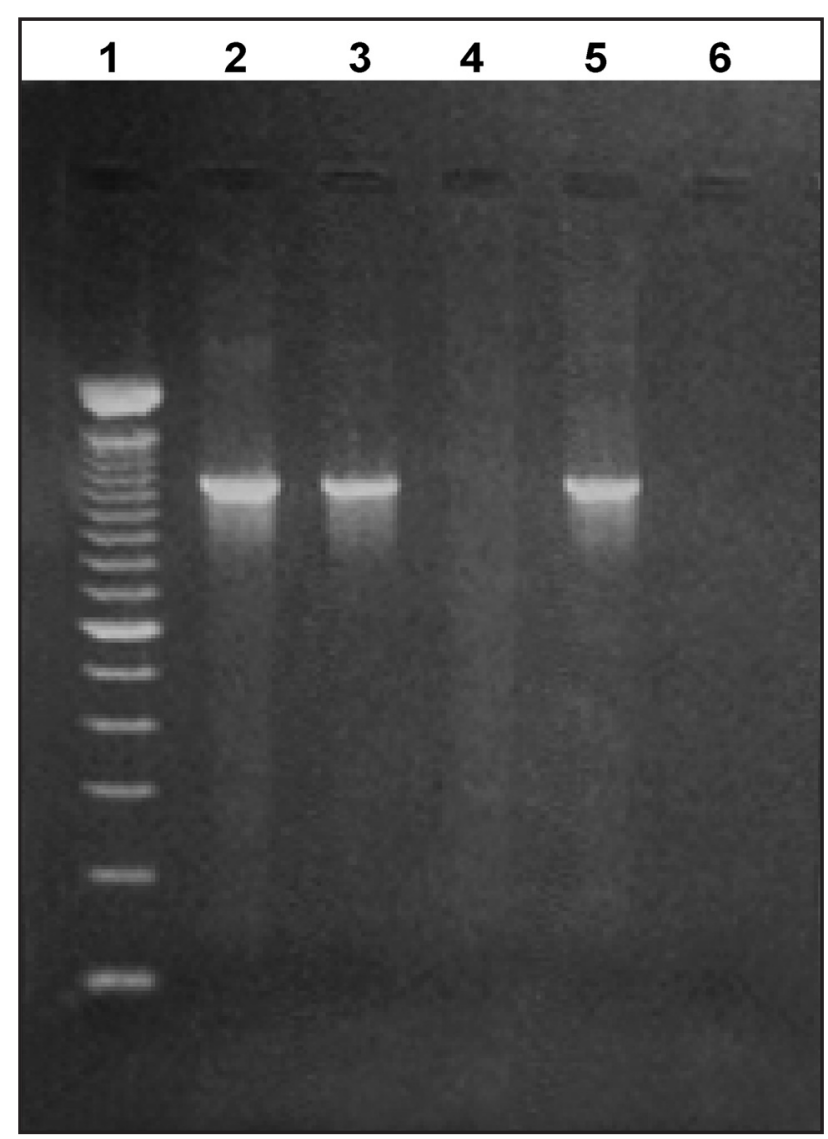

FIGURA 1

Reação de PCR: 1. Marcador de peso molecular. 2. Crosta macerada. 3. Líquido vesicular. 4. Crosta macerada negativa. 5. Vírus vaccinia amostra Wyeth. $6 . \mathrm{H}_{2} 0$.

Um total de 68 (85\%) casos foi confirmado como uma infecção por orthopoxvirus através das técnicas laboratoriais acima descritas, tendo sido isoladas 21 amostras de vírus. Nos espécimens obtidos de lesões de pele, a reação de PCR e o isolamento viral apresentaram sensibilidades comparáveis.

Em relação às amostras de soro, foi possível determinar anticorpos para orthopoxvirus em 49 delas, com títulos iguais ou superiores a 1/20. Não se pode eliminar a possibilidade de que alguns destes casos possuíam anticorpos residuais das campanhas de vacinação, realizadas na década de 1960. Embora o dado sobre a idade dos pacientes não seja disponível para a quase totalidade dos casos, pela experiência obtida no campo na investigação de casos no Estado do Rio de Janeiro, tratava-se de populações jovens, com idade inferior a 40 anos, na grande maioria dos casos.

Amicroscopia eletrônica apresentou a mais baixa sensibilidade, confirmando a literatura disponível, uma vez que a prova exige, no mínimo, a presença de cerca de 100.000 partículas de vírus no espécimen para que as mesmas sejam visualizadas.

o quadro clínico dos pacientes, quando relatado, indicava a presença de lesões dolorosas que surgiam nos membros superiores, em especial nas mãos. Iniciando-se como máculas e pápulas, as lesões evoluíam para vesículas, pústulas e crostas, as quais com frequência apresentavam infecções secundárias. Lesões faciais foram igualmente observadas, sendo descrito um caso de lesão vulvar (Figura 2). 


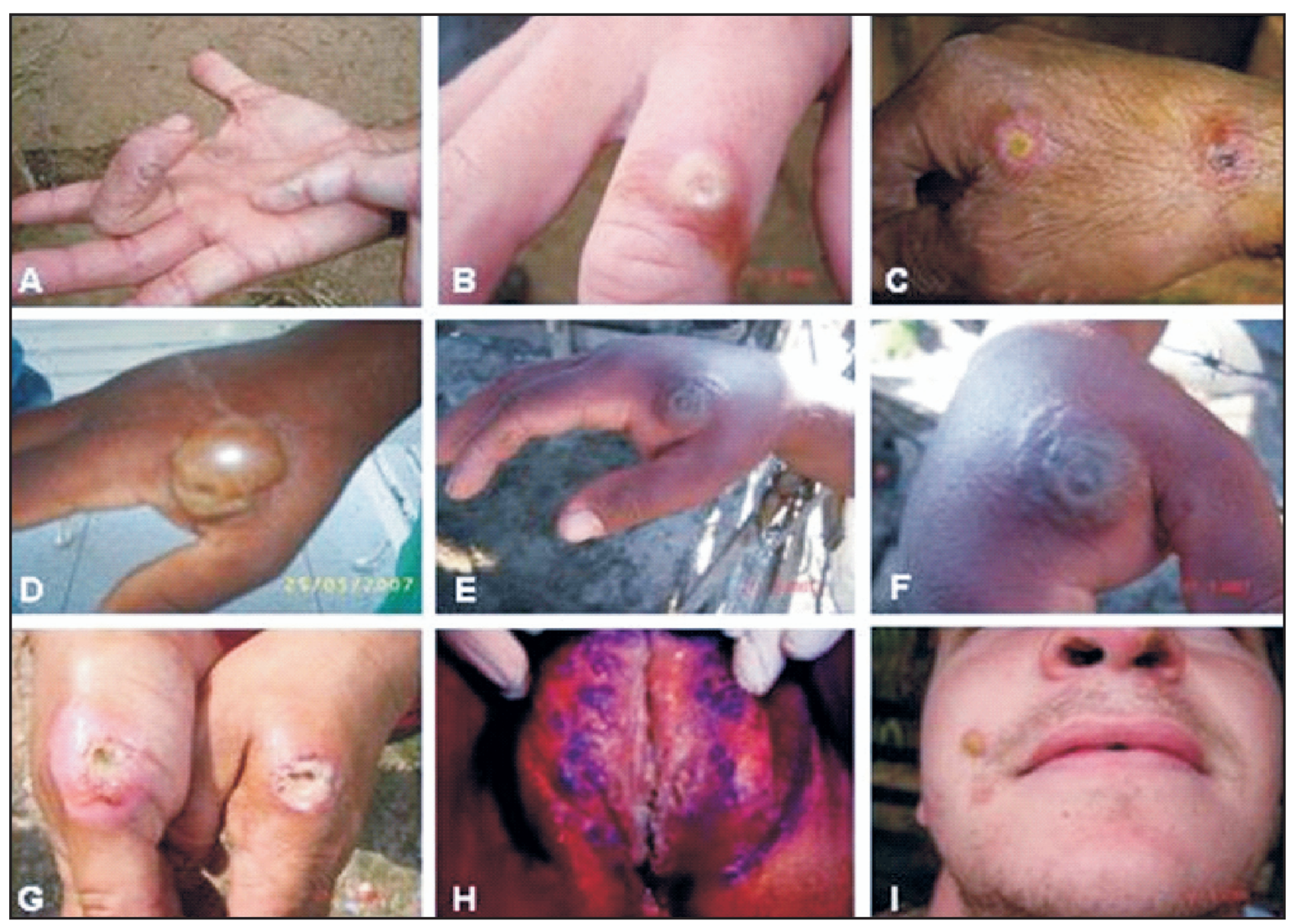

FIGURA 2

Lesões de casos confirmados de infecções por poxvirus relacionados ao vírus vaccinia. A-G: lesões nas mãos em diferentes estágios de evolução. H. lesão vulvar (reprodução autorizada de Virus Reviews \& Research). I. lesões na face.

A maioria dos pacientes apresentou quadro febril, com reação ganglionar axilar por vezes dolorosa, cefaléia, prostração, desidratação, anorexia, sudorese, artralgia, mialgia e as lesões de face eram acompanhadas por vezes, de reação ganglionar cervical anterior ${ }^{3} 101417182021$. O quadro clínico é autolimitado, sendo necessário apenas tratamento sintomático e controle de infecções secundárias. Entretanto, a internação de pacientes mais graves ocorreu em alguns casos, devido ao estado geral comprometido. Em todos os pacientes se relatava o contato com bovinos produtores de leite, os quais apresentavam vesículas, pústulas ou crostas no úbere. Ordenhadores constituíram a grande maioria dos casos, sendo que a transmissão sempre ocorreu de animal para o homem, exceto um caso no qual uma infecção intrafamiliar foi relatada ${ }^{1}$.

Dentro do conceito de que as amostras do vírus vaccinia estão circulando na natureza, torna-se importante comprovar quais seriam os reservatórios destes vírus. Neste sentido, um programa de coleta de roedores silvestres para pesquisa de vírus e anticorpos para poxvirus no Estado do Rio de Janeiro está sendo desenvolvido.

\section{DISCUSSÃO}

A transmissão do vírus vaccinia a partir de vacinados foi observada com relativa frequência, quando ainda se imunizava populações contra a varíola ${ }^{18}$. Um caso foi descrito, recentemente, envolvendo um militar americano $0^{12}$. Infecções de bovinos a partir de vacinados foram igualmente assinaladas, confirmando-se a capacidade do vírus vaccinia de atingir diferentes espécies na natureza ${ }^{11} 1324$. Com a suspensão das vacinações no Brasil, na década de 1970, era esperado o desaparecimento total de casos humanos de infecções por vaccinia, o que não ocorreu.

A partir do final do século passado, começaram a ser observados casos humanos, após contato com bovinos produtores de leite, especialmente no sudeste do país. Estas infecções, embora não sejam de notificação compulsória, considerando os dados disponíveis, devem atingir na atualidade pelo menos oito estados, apresentando nos pacientes sintomas clínicos e quadros epidemiológicos semelhantes ${ }^{25}$. No Estado do Rio de Janeiro, as infecções humanas e/ou de animais foram confirmadas clínica e laboratorialmente em 12 municípios $^{321}$.

Uma avaliação da literatura mostra que, em 1963, uma amostra de poxvirus semelhante ao vírus vaccinia foi isolada do sangue de um roedor silvestre do gênero Oryzomys sp no Estado do Pará ${ }^{6}$. Posteriormente, outra amostra semelhante ao vírus vaccinia, denominada Cotia, foi obtida de um roedor sentinela pelo Instituto Adolpho Lutz, em área de preservação ambiental no Estado de São Paulo ${ }^{23}{ }^{26}$. Estes dados sugerem que roedores silvestres e artrópodos podem estar infectados com poxvirus semelhantes ou derivados do vírus vaccinia, há várias décadas. 
Por outro lado, confirmando a capacidade dos poxvirus de se adaptarem a roedores, sabe-se que o vírus cowpox, não existente nas Américas, circula na natureza em roedores silvestres europeus como Microtus agrestis e em Rattus norvergicus, tendo sido descritos casos humanos a partir de contacto com estas espécies ou com felinos igualmente infectados, após contacto com roedores.

Recentes revisões enfatizam a capacidade dos poxvirus de se adaptarem a roedores e reconhecem a existência em nosso país de casos humanos causados por vírus relacionados ao vírus vaccinia ${ }^{9,15}$.

No subcontinente indiano, tem sido observada igualmente, com crescente intensidade, a presença de uma infecção por poxvirus transmitida ao homem através do contacto com búfalos (Bubalus bubalis), em distintas regiões daquele país. 0 orthopoxvirus responsável pelo quadro, denominado buffalopox, apresenta características filogenéticas muito próximas ao vírus vaccinia, admitindo-se como muito provável ser uma variante do mesmo ${ }^{22}$. Estes vírus teriam se adaptado ao búfalo e/ou outro animal reservatório após as grandes campanhas de vacinação contra a varíola, realizadas naquele país, um evento aparentemente muito semelhante ao que está ocorrendo no Brasil.

Por outro lado, sabe-se que quatro laboratórios produziram no Brasil vacina antivaríolica, durante a campanha de erradicação da doença. Com isto, diferentes amostras do vírus vaccinia foram usadas nesta produção. Em um dos Laboratórios (Instituto Oswaldo Cruz) foram produzidos dois tipos de vacina, em vitelos e em ovos embrionados. Estudos moleculares confirmaram que vírus isolados de bovinos e humanos na última década, todos relacionados molecularmente ao vírus vaccinia, realmente apresentam diferenças genéticas entre $\mathrm{si}^{5}$.

No entanto, estas diferenças não têm aparentemente influenciado a apresentação dos quadros clínicos que vem sendo relatados em humanos e em animais, à medida que se observa uma expansão da zoonose no país.

Ainfecção da vulva por amostras vacinais foi descrita em diversas oportunidades $^{812}$ ao longo das campanhas de vacinação. Um caso publicado recentemente no Brasil ${ }^{1}$ relata infecção vulvar através de contágio intrafamiliar, a partir do marido apresentando lesões nas mãos, após contato com animais, sendo a primeira descrição no país deste quadro clínico relacionado a esta zoonose.

Como diagnóstico diferencial da infecção por orthopoxvirus podemos citar parapoxvirus, herpes simplex, esporotricose, eventualmente antrax e abcessos por estafilococos. Aspecto a se considerar é a importância da imunidade celular para o controle das infecções por poxvirus. 0 uso de corticóides sistêmicos, bem como a presença de dermatite atópica no paciente, constituem fatores de risco para o agravamento da infecção, da mesma forma que síndromes de imunodeficiência natural ou adquirida, como as infecções pelo vírus HIV.

Considerando que as perdas econômicas causadas pela infecção de bovinos são por vezes importantes e os bovinos constituem a fonte primária da infecção humana, deve ser considerada a possibilidade de vacinação destes animais, nas regiões mais atingidas.
Em conclusão, considera-se que maior atenção deve ser dada aos casos desta zoonose, a qual se apresenta como uma doença vesicular/pustular aguda, no sentido de seu correto diagnóstico e adequada terapia de suporte, orientando-se os pacientes no sentido de evitar a transmissão intrafamiliar, bem como para animais com os quais venham a ter contato, considerando que a quase totalidade dos casos ocorre em áreas rurais. Ressalte-se a importância dos profissionais que atendem os animais, como os médicos-veterinários, na orientação aos ordenhadores sobre 0 manejo de infecções por poxvirus.

\section{REFERÊNCIAS}

1. Batista VH, Scremin J, Aguiar LM, Schatzmayr HG. Vulvar infection and possible human-to-human transmission of bovine poxvirus disease. (disponível em http://www.sbv.org.br). Virus Reviews \& Research 14:1-10, 2009.

2. Brenner S, Horne RW. A negative staining method for high-resolution electron microscopy of viruses. Biochemical Biophsysical Acta 34:103-104, 1959.

3. Costa RVC, Simonetti BR, Abreu DC, Simonetti JP, Gonçalves MCR, Silva MEV, Brust LAC, Barth OM, Schatzmayr HG. Animal infections by vaccinia-like viruses in the state of Rio de Janeiro: 2 - Paraíba river valley. (disponível em http://www. sbv.org.br) Virus Reviews \& Research 12:33-37, 2007.

4. Damaso CRA, Esposito JJ, Condit RC, Moutssatché N. An emergent poxvirus from humans and cattle in Rio de Janeiro state: Cantagalo virus may derive from Brazilian smallpox vaccine. Virology 277:439-449, 2000.

5. De Souza Trindade G, Fonseca FG, Marques JT, Nogueira ML, Mendes LC, Borges AS, Peiró JR, Pittuco EAM, Bonjardim CA, Ferreira PC, Kroon EG. Araçatuba virus: a vaccinia like virus associated with infection in humans and cattle. Emerging Infectious Diseases 9:155-160, 2003.

6. Fonseca FG, Lanna MCS, Campos MAS, Kitajima EW, PerezJN, Golgher RR, Ferreira PCP, Kroon EG. Morphological and molecular characterization of the poxvirus BeAn 58058. Archives of Virology 143:1171-1186, 1998.

7. Guarner J, Johnson BJ, Paddock CD, Shieh WJ, Goldsmith CS, Reynolds MG, Damon IK, Regnery RL, Zaki SR. Monkeypox transmission and pathogenesis in prairie dogs. (disponível em: http://cdc.gov/ncidod/EID/vol10no3/03-0878.htm) Emerging Infectious Diseases. (Série on-line março 2004).

8. Humphrey DC. Localized accidental vaccinia of the vulva: report of three cases and a review of the world literature. American Obstetrics and Gynecology 86:460-469, 1963.

9. Lewis-Jones S. Zoonotic poxvirus infections in humans. Current Opinion in Infectious Diseases 17:81-89, 2004.

10. Lobato ZIP, Trindade GS, Frois MCM, Ribeiro EBT, Dias GRC, Teixeira BM, Lima GMF, Almeida GMF, Kroon EG. Surto de varíola bovina causada pelo vírus vaccinia na região da Zona da Mata Mineira. Arquivo Brasileiro de Medicina Veterinária e Zootecnia 57:423-429, 2005.

11. Lum GS, Soriano F, Trejos A, Lierena J. Vaccinia epidemic and epizootic in El Salvador. The American Journal of Tropical Medicine and Hygiene 16:332-338, 1967.

12. McLaughlin J, Schmidt T, Westcott M, Baumbach J, Lofgren JP, Gerber S, Panares R, Staggs W, Collins L, Tong S, Li Y, Mar E, Ruone S, LaMonte-Fowlkes MA, Anderson L, Reynolds M, Trindade G, Olson V, Damon A, Fagan R, Lederman E. Vulvar vaccinia infection after sexual contact with a military smallpox vaccinee-Alaska, 2006. Morbidity and Mortality Weekly Report/CDC 56:417-419, 2007.

13. Mesquita JA, Schatzmayr HG. Estudos laboratoriais de infecções humanas e de bovinos com vírus do grupo Pox. Revista da Sociedade Brasileira de Medicina Tropical 3:171-175, 1969.

14. Nagasse-Sugahara TK, Kisielius JJ, Ueda-Ito M, Curti SP, Figueiredo CA, Cruz AS. Human vaccinia-like virus outbreaks in São Paulo and Goias States, Brazil: virus detection, isolation and identification. Revista do Instituto de Medicina Tropical de São Paulo 46:315-322, 2004

15. Regnary RL. Poxvirus and the passive quest for novel hosts. Currents Topics on Microbiology and Immunology 315:345-361, 2007. 
16. Schatzmayr HG, Costa EA. Poxvirus. In: Coura JR (ed) Dinâmica das Doenças Infecciosas e Parasitárias, $1^{a}$ edição, Editora Guanabara, Rio de Janeiro, p. 1936-1944, 2005

17. Schatzmayr HG, Lemos ERS, Mazur, C, Schubach A, Majerowicz S, Rozental T, Schubach TMP, Bustamante MC, Barth OM. Detection of poxvirus in cattle associated with human cases in the state of Rio de Janeiro: preliminary report. Memórias do Instituto Oswaldo Cruz 95:625-627, 2000

18. Schatzmayr HG, Romjin PC, Barreto DF, Silva EE, Farias Filho JC, Tavares AFA, Barth OM. An outbreak of vesicopustular disease in humans and dairy cattle in the state of Rio de Janeiro in 2006. Virus Reviews \& Research 10:61-63, 2006

19. Sepkowitz KA. How contagious is vaccinia? New England Journal of Medicine 348:439-446, 2003

20. Silva AC, Reis BB, Ricci Junior JER, Fernandes FS, Corrêa JF, Schatzmayr HG. Infecção em humanos por varíola bovina na microrregião de Itajubá, Estado de Minas Gerais: relato de caso. Revista da Sociedade Brasileira de Medicina Tropical 41:507-511, 2008
21. Simonetti BR, Abreu DC, Simonetti JP, Gonçalves MCR, Silva MEV, Barth OM, Schatzmayr HG. Animal infections by vaccinia-like viruses in the state of Rio de Janeiro: 1- Northwestern region. (disponível em http://www.sbv.org.br). Virus Reviews \& Research 12:32-36, 2007.

22. Singh RK, Hosamani M, Balamurugan V, Bhanuprakash V, Rasool TJ, Yadad MP Bufallopox: an emerging and re-emerging zoonosis. Animal Health Research and Reviews 8:105-114, 2007.

23. Souza-Lopes 0, Lacerda JPG, Fonseca IEM, Castro DP, Forattini OP, Rabello EX. Cotia vírus: a new agent isolated from sentinel mice in São Paulo. The American Journal of Tropical Medicine and Hygiene 14:156-157, 1965.

24. Topciu V, Luca I, Moldovan E, Stoianovici V, Plavosin L, Milin D. Transmission of vaccinia virus from vaccinated milkers to cattle. Virology 27:279-282, 1976.

25. Trindade GS, Emerson GL, Carroll DS, Kroon EG, Damon IK. Brazilian vaccinia viruses and their origins. Emerging Infectious Diseases 13:965-972, 2007.

26. Ueda Y, Tsuruhara KR, Tagaya T. Studies on Cotia virus - an unclassified poxvirus Journal General Virology 40:263-276, 1978 